\title{
ARTICLE
}

Clinical Study

\section{Randomised Phase 1b/2 trial of tepotinib vs sorafenib in Asian patients with advanced hepatocellular carcinoma with MET overexpression}

\author{
Baek-Yeol Ryoo $\mathbb{D}^{1}$, Ann-Li Cheng $\mathbb{D}^{2}$, Zhenggang Ren ${ }^{3}$, Tae-You Kim ${ }^{4}$, Hongming Pan ${ }^{5}$, Kun-Ming Rau ${ }^{6}$, Hye Jin Choi $\mathbb{D}^{7}$, \\ Joong-Won Park ${ }^{8}$, Jee Hyun Kim ${ }^{9}$, Chia Jui Yen ${ }^{10}$, Ho Yeong Lim ${ }^{11}$, Dongli Zhou ${ }^{12}$, Josef Straub ${ }^{13}$, Juergen Scheele ${ }^{14}$, \\ Karin Berghoff ${ }^{15}$ and Shukui Qin ${ }^{16}$
}

BACKGROUND: This open-label, Phase $1 \mathrm{~b} / 2$ study evaluated the highly selective MET inhibitor tepotinib in systemic anticancer treatment (SACT)-naive Asian patients with advanced hepatocellular carcinoma (aHCC) with MET overexpression.

METHODS: In Phase $2 \mathrm{~b}$, tepotinib was orally administered once daily $(300,500$ or 1,000 mg) to Asian adults with aHCC. The primary endpoints were dose-limiting toxicities (DLTs) and adverse events (AEs). Phase 2 randomised SACT-naive Asian adults with aHCC with MET overexpression to tepotinib (recommended Phase 2 dose [RP2D]) or sorafenib $400 \mathrm{mg}$ twice daily. The primary endpoint was independently assessed time to progression (TTP).

RESULTS: In Phase 1b $(n=27)$, no DLTs occurred; the RP2D was $500 \mathrm{mg}$. In Phase $2(n=90,45$ patients per arm), the primary endpoint was met: independently assessed TTP was significantly longer with tepotinib versus sorafenib (median 2.9 versus 1.4 months, $\mathrm{HR}=0.42,90 \%$ confidence interval: $0.26-0.70, P=0.0043$ ). Progression-free survival and objective response also favoured tepotinib. Treatment-related Grade $\geq 3 \mathrm{AE}$ rates were $28.9 \%$ with tepotinib and $45.5 \%$ with sorafenib.

CONCLUSIONS: Tepotinib improved TTP versus sorafenib and was generally well tolerated in SACT-naive Asian patients with aHCC with MET overexpression.

TRIAL REGISTRATION: ClinicalTrials.gov NCT01988493.

British Journal of Cancer (2021) 125:200-208; https://doi.org/10.1038/s41416-021-01380-3

\section{BACKGROUND}

Hepatocellular carcinoma (HCC) is the most common type of primary liver cancer in adults. ${ }^{1}$ Its incidence is rising alongside increasing rates of chronic liver disease. For many years, the only approved targeted systemic therapy for advanced HCC was the nonselective multikinase inhibitor sorafenib. ${ }^{2,3}$ This agent provides only a modest improvement in overall survival (OS) and may not be as well tolerated by Asian patients compared with those of other ethnicities. ${ }^{4,5}$ Newer first-line treatment options include the multikinase inhibitor lenvatinib and the immunotherapy atezolizumab (in combination bevacizumab), which have been approved following positive data from randomised Phase 3 trials versus sorafenib., , $^{3} 8$

MET is the tyrosine kinase receptor for hepatocyte growth factor (HGF). ${ }^{9}$ Approximately $50 \%$ of patients with HCC may harbour MET alterations, ${ }^{9}$ and $28 \%$ of patients with advanced HCC show evidence of MET overexpression. ${ }^{10}$ These patients may derive therapeutic benefit from selective MET inhibition. ${ }^{9,11}$ In vitro, MET inhibitors can reduce the growth of MET-positive HCC cell linederived xenograft models. ${ }^{11}$

Tepotinib is an orally available, potent and highly selective MET inhibitor that has shown pronounced antitumour activity in METdependent preclinical mouse models in vivo. ${ }^{12,13}$ In a first-inhuman study in US/European patients with various solid cancers (including $\mathrm{HCC}$ ), tepotinib was generally well tolerated and demonstrated activity in tumours harbouring MET alterations. ${ }^{13}$ Tepotinib also showed durable clinical activity and was generally well tolerated in a Phase 2 study in patients with non-small cell lung cancer with MET exon 14 skipping, in which consistent

\footnotetext{
${ }^{1}$ Department of Oncology, Asan Medical Center, University of Ulsan College of Medicine, Seoul, Republic of Korea; ${ }^{2}$ Department of Oncology, National Taiwan University Hospital,

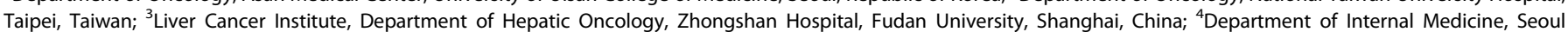

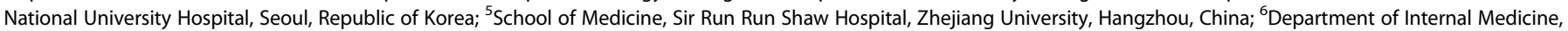

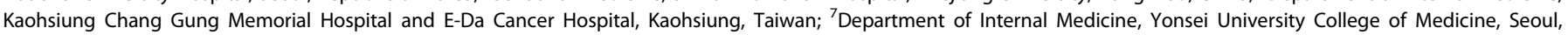

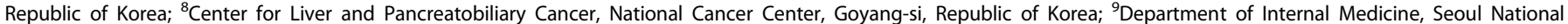

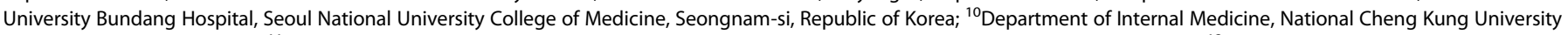

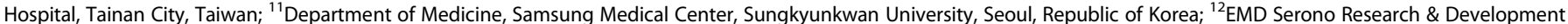

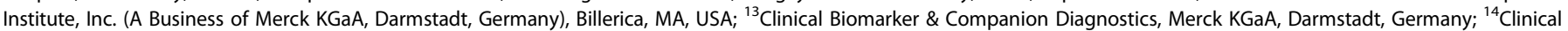

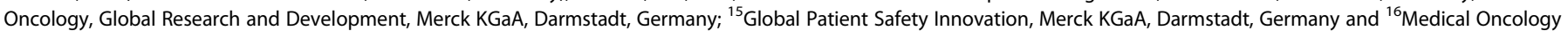
Department, PLA Cancer Center, Nanjing Bayi Hospital, Nanjing, China
}

Correspondence: Baek-Yeol Ryoo (ryooby@amc.seoul.kr)

Received: 2 October 2020 Revised: 10 March 2021 Accepted: 25 March 2021

Published online: 10 May 2021 
activity was observed in the subgroup of Asian patients. ${ }^{14,15}$ Furthermore, in combination with gefitinib, tepotinib has demonstrated improved efficacy compared with chemotherapy in patients with advanced epidermal growth factor receptormutant non-small cell lung cancer and MET-driven resistance to epidermal growth factor receptor (EGFR) inhibitors ${ }^{16}$ and a Phase 2 study of tepotinib plus osimertinib in patients with acquired resistance to first-line osimertinib due to MET amplification is ongoing (INSIGHT 2, NCT03940703). A Phase 2 study is also underway investigating tepotinib in combination with cetuximab in patients with RAS/BRAF wild-type left-sided metastatic colorectal cancer and acquired resistance to anti-EGFR antibodytargeted therapy due to MET amplification (NCT04515394).

Following preclinical data demonstrating activity of tepotinib against primary liver cancer explants with MET overexpression, ${ }^{12}$ two Phase $1 \mathrm{~b} / 2$ studies were designed to investigate tepotinib in patients with HCC with MET overexpression. In the first of these (NCT02115373), tepotinib demonstrated clinical activity and was generally well tolerated in US/European patients in whom prior sorafenib treatment had failed. ${ }^{17}$ Here, we present the second trial in HCC, which was conducted in Asian patients (NCT01988493). Since patients with hepatic impairment were excluded from the first-in-human trial, ${ }^{13}$ the trial included a Phase $1 \mathrm{~b}$ part to establish the recommended Phase 2 dose (RP2D) of tepotinib in patients with HCC and Child-Pugh Class A liver function. The Phase 2 part of the trial then evaluated the activity and safety of the RP2D of tepotinib versus sorafenib in systemic anticancer treatment (SACT)-naive Asian patients with MET overexpression.

\section{METHODS}

Study design and objectives

This was an open-label, multicentre, integrated, Phase $1 \mathrm{~b} / 2$ trial conducted in Asian patients with advanced HCC (NCT01988493). The Phase $1 \mathrm{~b}$ part of the trial was an open-label, single-arm, doseescalation study with a classic ' $3+3$ ' design and a primary objective to establish the RP2D of tepotinib. The Phase 2 part was a multicentre, randomised, open-label, active-controlled study to evaluate the activity and safety of tepotinib as monotherapy versus sorafenib (Supplementary Fig. 1). Phase 1b was conducted at eight sites and Phase 2 at 43 sites in mainland China, South Korea and Taiwan.

All patients provided written informed consent for participation in the study. The study was done in accordance with the Declaration of Helsinki, International Council for Harmonization guideline for Good Clinical Practice, local laws and applicable regulatory requirements. The study was approved by the institutional review board or independent ethics committee of each centre.

\section{Patients}

Patients were enrolled by the investigators. In both study phases, eligible patients were Asian and aged $\geq 18$ years with histologically or cytologically confirmed HCC of Barcelona Clinic liver cancer $(B C L C)$ stage $B$ or $C$ with Child-Pugh Class A liver function, and Eastern Cooperative Oncology Group performance status 0 or 1. Exclusion criteria included prior treatment with any agent targeting the HGF/MET pathway, prior local-regional therapy within 4 weeks before Day 1 of study treatment and presence of symptomatic or untreated brain metastases.

Based on a local regulatory requirement, patients enrolled in South Korea in Phase $1 \mathrm{~b}$ were required to have experienced disease progression or intolerance to prior standard treatment for advanced HCC. In Phase 2, prior SACT for advanced HCC was not allowed. Eligibility for Phase 2 also required MET overexpression, as determined during molecular pre-screening or screening by immunohistochemistry $(\mathrm{IHC})$ analysis of tumour biopsy samples using the pharmDx anti-total MET (D1C2) rabbit monoclonal antibody (Dako, Agilent Technologies, Inc., Santa Clara, CA, US) (Supplementary Table 1). MET overexpression was defined as moderate $(2+)$ or strong $(3+)$ staining for MET in $\geq 50 \%$ of tumour cells. Due to a quality issue in central MET IHC assessments detected during routine monitoring, central re-scoring of all MET $\mathrm{IHC}$ analyses was conducted after enrolment as a quality control measure. MET expression status assessment was not required for Phase $1 \mathrm{~b}$, but was determined retrospectively. In Phase 2, MET amplification was assessed retrospectively by fluorescence in situ hybridisation using the Dako MET IQFISH probe (Agilent Technologies, Inc.) and defined by mean MET gene copy number $\geq 5$. ${ }^{18}$ Full inclusion and exclusion criteria are shown in Supplementary Table 2.

\section{Treatment administration}

In Phase $1 \mathrm{~b}$, patients were treated orally, once daily (QD), in 21day cycles with tepotinib hydrochloride hydrate $300 \mathrm{mg}, 500 \mathrm{mg}$ or $1,000 \mathrm{mg}$ (containing 270, 450 and $900 \mathrm{mg}$, respectively, of the active moiety in free base form). The target RP2D was defined as $500 \mathrm{mg}$, based on the results of the first-in-human trial. ${ }^{13}$ Patients enrolled in South Korea and Taiwan received tepotinib according to a classic ' $3+3$ ' dose-escalation design at $300 \mathrm{mg}$ or $500 \mathrm{mg}$. Once three patients had completed one cycle at $500 \mathrm{mg}$, nine further patients were to be enrolled at this dose level to confirm the RP2D. Patients were replaced if they discontinued during Cycle 1 for reasons other than a dose-limiting toxicity (DLT), or if they did not receive $\geq 80 \%$ of the planned dose during Cycle 1 for reasons other than DLTs or adverse events (AEs) related to tepotinib. The Safety Monitoring Committee (SMC) could also recommend enrolment of additional patients at or above the RP2D. Although no DLTs were observed, the SMC recommended the enrolment of a further three patients at $300 \mathrm{mg}$ to provide additional data at this dose level. After the RP2D had been defined at $500 \mathrm{mg}$ and in parallel with the Phase 2 part of the study, the SMC also recommended enrolment of six patients in South Korea to receive tepotinib at $1,000 \mathrm{mg}$, to enable characterisation of safety and pharmacokinetics of this dose. Separate from the ' $3+3$ ' dose-escalation cohorts, up to three patients were to be enrolled in mainland China to receive tepotinib $300 \mathrm{mg}$.

In Phase 2, patients were treated with tepotinib orally QD at the RP2D, or with sorafenib $400 \mathrm{mg}$ orally twice daily. Patients in both phases continued to receive allocated therapy until disease progression, intolerable toxicity or withdrawal of consent.

\section{Randomisation and masking}

In Phase 2, patients were randomly allocated to receive tepotinib or sorafenib in a 1:1 ratio. The randomisation sequence was computer-generated by the sponsor and implemented via an interactive voice-response system (which also concealed the sequence). A stratified, permuted block randomisation procedure (block size of 6 , with sub-block sizes of 4 and 2) was used with $B C L C$ stage $B$ versus $C$ as the strata criteria. Neither clinicians nor patients were blinded to treatment selection.

\section{Study endpoints and assessments}

In Phase $1 b$, the primary endpoint was the incidence of investigator-assessed DLTs occurring in Cycle 1, as well as the incidence of other AEs (graded according to the National Cancer Institute Common Terminology and Criteria for Adverse Events, v4.0). DLTs are defined in Supplementary Table 3. Secondary endpoints in Phase 1b included efficacy measures and pharmacokinetic parameters, such as $C_{\max }$ and area under the concentration-time curve over the dosing interval at steady state $\left(A \cup C_{\mathrm{t}, \mathrm{ss}}\right)$, which were evaluated at Cycle 1, Day 15.

In Phase 2, the primary endpoint was independent review committee (IRC)-assessed time to progression (TTP) per Response Evaluation Criteria in Solid Tumors (RECIST) v1.1. Secondary endpoints included investigator-assessed TTP, IRC- and 
Table 1. Baseline characteristics (Phase 2 study; mITT population ${ }^{\mathrm{a}}$ ).

\begin{tabular}{|c|c|c|c|}
\hline & $\begin{array}{l}\text { Tepotinib } \\
n=38\end{array}$ & $\begin{array}{l}\text { Sorafenib } \\
n=37\end{array}$ & $\begin{array}{l}\text { Total } \\
n=75\end{array}$ \\
\hline Median (range) age, years & $59(38-78)$ & $54(31-78)$ & $57(31-78)$ \\
\hline Aged <65 years, $n(\%)$ & $31(81.6)$ & $32(86.5)$ & $63(84.0)$ \\
\hline Male, $n(\%)$ & $37(97.4)$ & 34 (91.9) & $71(94.7)$ \\
\hline \multicolumn{4}{|l|}{ Region, $n$ (\%) } \\
\hline Mainland China & $14(36.8)$ & $12(32.4)$ & $26(34.7)$ \\
\hline Republic of Korea & $18(47.4)$ & $19(51.4)$ & $37(49.3)$ \\
\hline Taiwan & $6(15.8)$ & $6(16.2)$ & $12(16.0)$ \\
\hline \multicolumn{4}{|c|}{ Prior local-regional anticancer therapy, $n(\%)$} \\
\hline Yes & $20(52.6)$ & $20(54.1)$ & $40(53.3)$ \\
\hline No & $18(47.4)$ & $17(45.9)$ & $35(46.7)$ \\
\hline \multicolumn{4}{|l|}{ HBV test, $n(\%)$} \\
\hline Positive & $24(63.2)$ & $30(81.1)$ & $54(72.0)$ \\
\hline Negative & $10(26.3)$ & $6(16.2)$ & $16(21.3)$ \\
\hline Missing & $4(10.5)$ & $1(2.7)$ & $5(6.7)$ \\
\hline \multicolumn{4}{|l|}{ HCV test, $n(\%)$} \\
\hline Positive & $2(5.3)$ & $5(13.5)$ & $7(9.3)$ \\
\hline Negative & $22(57.9)$ & $21(56.8)$ & $43(57.3)$ \\
\hline Missing ${ }^{\mathrm{b}}$ & $14(36.8)$ & $11(29.7)$ & $25(33.3)$ \\
\hline \multicolumn{4}{|l|}{$\mathrm{HBV} / \mathrm{HCV}$ at baseline, $n(\%)$} \\
\hline Either positive & $24(63.2)$ & $30(81.1)$ & $54(72.0)$ \\
\hline $\begin{array}{l}\text { Both negative or one negative/ } \\
\text { one missing }\end{array}$ & $10(26.3)$ & $6(16.2)$ & $16(21.3)$ \\
\hline Both missing & $4(10.5)$ & $1(2.7)$ & $5(6.7)$ \\
\hline \multicolumn{4}{|l|}{ Alcohol use, $n(\%)$} \\
\hline Never & $13(34.2)$ & $14(37.8)$ & $27(36.0)$ \\
\hline Regular & $5(13.2)$ & $4(10.8)$ & $9(12.0)$ \\
\hline Occasional & $0(0.0)$ & $1(2.7)$ & $1(1.3)$ \\
\hline Former & $20(52.6)$ & $18(48.6)$ & $38(50.7)$ \\
\hline \multicolumn{4}{|l|}{ AFP, $n(\%)$} \\
\hline$\geq 200 \mathrm{IU} / \mathrm{mL}$ & $22(57.9)$ & $24(64.9)$ & $46(61.3)$ \\
\hline$<200 \mathrm{IU} / \mathrm{mL}$ & $16(42.1)$ & $13(35.1)$ & $29(38.7)$ \\
\hline \multicolumn{4}{|l|}{ Vascular invasion, $n(\%)$} \\
\hline Yes & $12(31.6)$ & $15(40.5)$ & $27(36.0)$ \\
\hline No & $16(42.1)$ & $6(16.2)$ & $22(29.3)$ \\
\hline Missing & $10(26.3)$ & $16(43.2)$ & $26(34.7)$ \\
\hline \multicolumn{4}{|l|}{ BCLC stage, $n(\%)$} \\
\hline B & $2(5.3)$ & $2(5.4)$ & $4(5.3)$ \\
\hline $\mathrm{C}$ & $36(94.7)$ & $35(94.6)$ & $71(94.7)$ \\
\hline \multicolumn{4}{|l|}{ MET IHC, $n(\%)$} \\
\hline $\mathrm{IHC} 2+$ & $36(94.7)$ & $24(64.9)$ & $60(80.0)$ \\
\hline $\mathrm{IHC} 3+$ & $2(5.3)$ & $13(35.1)$ & $15(20.0)$ \\
\hline \multicolumn{4}{|l|}{ MET amplification, ${ }^{c} n(\%)$} \\
\hline Present & $4(10.5)$ & $5(13.5)$ & $9(12.0)$ \\
\hline Absent & $32(84.2)$ & $32(86.5)$ & $64(85.3)$ \\
\hline Missing & $2(5.3)$ & $0(0.0)$ & $2(2.7)$ \\
\hline
\end{tabular}

AFP alpha-fetoprotein, $B C L C$ Barcelona Clinic liver cancer, GCN gene copy number, $H B V$ hepatitis $B$ virus, $H C V$ hepatitis $C$ virus, $I H C$ immunohistochemistry, IU international units, $\mathrm{m} / \mathrm{TT}$ modified intention-to-treat.

${ }^{a}$ mITT excludes patients that were MET IHC $1+$ or not assessable based on re-scoring.

${ }^{\mathrm{b}} \mathrm{HCV}$ testing was a late addition to the study protocol; therefore, $\mathrm{HCV}$ is missing for $25 / 75$ patients.

${ }^{\mathrm{C}} M E T$ amplification defined as mean $\mathrm{GCN} \geq 5$. investigator-assessed progression-free survival (PFS), objective response rate (ORR), disease control rate, OS and safety. In both phases, tumour assessments were performed according to RECIST v1.1 based on scans taken at the end of every second cycle until Cycle 13, and every four cycles thereafter.

Statistical analysis

Phase $1 \mathrm{~b}$ data were analysed in a descriptive manner; DLTs were assessed in all patients who experienced a DLT during Cycle 1 or completed at least $80 \%$ of planned treatment during the 21 days after the first dose of tepotinib.

In Phase 2, analyses were conducted according to randomised treatment assignment. TTP was analysed in a modified intentionto-treat $(\mathrm{mlTT})$ population, which included all patients randomised to study treatment for whom MET overexpression was confirmed during planned re-scoring of IHC analyses (i.e. patients with MET status $1+$ or 'not assessable' on re-scoring were excluded from the $\mathrm{mITT}$ population). In total, 100 TTP events were required to ensure $80 \%$ power (with a two-sided significance level of $10 \%$ ) for rejecting the null hypothesis of equal treatment effect between treatment arms, assuming a true hazard ratio (HR) of 0.6. With an assumed accrual period of 12 months, follow-up period of 6 months and overall drop-out rate of $17.4 \%, 140$ patients with HCC with MET overexpression were planned to be enrolled. The HR (including 90\% confidence interval [Cl], calculated by Cox's proportional hazards model, stratified by BCLC stage) and Kaplan-Meier survival estimates were used to compare TTP, PFS and OS between tepotinib and sorafenib. For the primary and secondary time-to-event endpoints, treatment groups were compared in the mITT population, applying a two-sided log-rank test, stratified by BCLC stage $(a=10 \%)$. Safety analyses in Phase 2 were conducted in all patients who received at least one dose of study medication. The data cut-off was May 31, 2017, for Phase 1b and March 12, 2018, for Phase 2.

\section{RESULTS}

Patients and treatment

Patients were enrolled between February 2014 and August 2017. Of 41 patients screened in Phase 1b (Supplementary Fig. 2a), 27 patients were recruited. All patients had discontinued treatment at data cut-off. Baseline characteristics are shown in Supplementary Table 4. The $300 \mathrm{mg}$ cohort comprised six patients who received tepotinib in the dose-escalation phase and one patient enrolled in mainland China. The $500 \mathrm{mg}$ cohort included three patients from the dose-escalation phase and nine from the dose-confirmation phase. A further two patients were enrolled at $500 \mathrm{mg}$ to replace patients not evaluable for DLTs (one due to Grade 2 bacteraemia, unrelated to tepotinib, and one due to disease progression). Six patients were enrolled at the $1,000 \mathrm{mg}$ dose level.

Enrolment into Phase 2 was stopped early due to slow accrual. A total of 619 patients entered pre-screening and 151 patients were screened for eligibility (Supplementary Fig. 2b). Of 592 patients assessed by IHC at pre-screening or screening, 161 (27.2\%) had MET overexpression in initial scoring. Ninety patients were randomised to treatment (tepotinib, $n=45$; sorafenib, $n=$ 45), which was lower than the enrolment target of 140 patients. One patient randomised to sorafenib did not receive any study treatment. After the exclusion of 15 patients who did not have MET overexpression on planned re-scoring of IHC analyses, the $\mathrm{mITT}$ population included 38 and 37 patients in the tepotinib and sorafenib arms, respectively. Baseline characteristics were generally similar between the tepotinib and sorafenib treatment arms in Phase 2, although more patients in the sorafenib arm had MET IHC $3+$ status $(35.1 \%)$ compared with the tepotinib arm (5.3\%) (Table 1). Median duration of tepotinib therapy was 12.7 weeks (interquartile range, 6.1-26.3), and median duration of sorafenib therapy was 11.9 weeks (interquartile range, 6.1-16.6). After 
discontinuation of study treatment, subsequent anticancer therapy was administered in 11 patients $(28.9 \%)$ in the tepotinib arm (including sorafenib in 10 patients, 26.3\%) and 17 patients $(45.9 \%)$ in the sorafenib arm.

\section{Safety}

No DLTs were established with any dose of tepotinib in Phase $1 \mathrm{~b}$, and, therefore, the RP2D of tepotinib was established as $500 \mathrm{mg}$ QD. All patients who received tepotinib in both Phase $1 \mathrm{~b}(n=27)$ and Phase $2(n=45)$ experienced AEs of any cause. In the sorafenib arm of Phase $2(n=44), 43$ patients $(97.7 \%)$ experienced AEs of any cause. In Phase 2, the most common AEs of any cause with tepotinib were peripheral oedema (42.2\%), diarrhoea (37.8\%) and decreased appetite (35.6\%), and with sorafenib were palmar-plantar erythrodysesthesia (61.4\%), decreased appetite $(40.9 \%)$, diarrhoea (38.6\%) and aspartate transaminase increase (36.4\%).

In Phase $1 \mathrm{~b}, 55.6 \%$ of patients receiving tepotinib experienced Grade $\geq 3$ AEs of any cause. In Phase 2, 60\% of patients receiving tepotinib and $70.5 \%$ of patients receiving sorafenib experienced Grade $\geq 3 \mathrm{AEs}$ of any cause. In Phase 2, permanent treatment discontinuation due to AEs of any cause occurred in seven patients $(15.6 \%)$ receiving tepotinib: these AEs were ascites $(n=$ $1)$, upper gastrointestinal haemorrhage $(n=1)$, fatigue $(n=2)$, hepatic failure $(n=1)$, QT interval prolongation $(n=1)$, and hepatic encephalopathy $(n=1)$. Six patients $(13.6 \%)$ receiving sorafenib permanently discontinued treatment due to AEs of any cause. Six patients (13.3\%) receiving tepotinib in Phase 2 died due to AEs of any cause. This was deemed to be treatment-related in one instance of upper gastrointestinal haemorrhage. Two patients receiving sorafenib died due to AEs while on treatment; neither were deemed treatment-related.

In Phase 2, AEs considered to be related to study treatment by the investigators were reported in $37(82.2 \%)$ of patients receiving tepotinib and $43(97.7 \%)$ of patients receiving sorafenib. Grade $\geq 3$ treatment-related AEs occurred in 13 (28.9\%) and 20 (45.5\%) patients receiving tepotinib and sorafenib, respectively (Table 2). The most common treatment-related $\mathrm{AEs}$ in patients receiving tepotinib were diarrhoea (35.6\%), peripheral oedema (24.4\%) and fatigue (20.0\%). For patients receiving sorafenib, the most common treatment-related AEs were palmar-plantar erythrodysesthesia (61.4\%), diarrhoea (31.8\%) and decreased appetite (27.3\%). The incidence of treatment-related AEs was similar in Phase $1 \mathrm{~b}$, with any-grade events observed in $22(81.5 \%)$ and Grade $\geq 3$ events in nine (33.3\%) patients receiving tepotinib (across all dose cohorts).

\section{Efficacy}

In Phase $1 \mathrm{~b}$, the best overall response was partial response (PR) in two patients: one in the $500 \mathrm{mg}$ cohort (ORR, 7.1\%) and one in the $1,000 \mathrm{mg}$ cohort (ORR, 16.7\%). Durations of PR were 19 months and 4.4 months, respectively. Tumour shrinkage was generally greater in patients with HCC with MET overexpression; both patients who achieved PR had HCC with MET overexpression $(n=$ 1, IHC 2+, 1,000 mg cohort, and $n=1, \mathrm{IHC} 3+, 500 \mathrm{mg}$ cohort) (Fig. 1). The disease control rate was $50 \%$ in the $500 \mathrm{mg}$ and 1,000 $\mathrm{mg}$ dose cohorts, and $14.3 \%$ in the $300 \mathrm{mg}$ cohort. In the $300 \mathrm{mg}$, $500 \mathrm{mg}$ and $1,000 \mathrm{mg}$ cohorts, most patients had a best overall response of stable disease $(14.3 \%, 42.9 \%$ and $33.3 \%$, respectively) or progressive disease $(85.7 \%, 35.7 \%$ and $50.0 \%$, respectively). ORRs and disease control rates in Phase $1 \mathrm{~b}$ suggested that efficacy increased with increasing dose.

The Phase 2 part of the study met its primary endpoint by demonstrating a significant improvement in IRC-assessed TTP in patients treated with tepotinib versus sorafenib $(H R=0.42,90 \%$ Cl: $0.26-0.70, P=0.0043$ ) (Fig. 2a). Median IRC-assessed TTP in the tepotinib arm was 2.9 months $(90 \% \mathrm{Cl}$ : $2.7-5.3)$ versus 1.4 months (90\% Cl: 1.4-1.6) in the sorafenib arm. In pre-planned subgroup

\begin{tabular}{|c|c|c|c|c|}
\hline \multirow{3}{*}{$\begin{array}{l}\text { Patients with } \\
\text { treatment-related } \\
\text { adverse events, } n \text { (\%) }\end{array}$} & \multicolumn{2}{|l|}{ Tepotinib } & \multicolumn{2}{|l|}{ Sorafenib } \\
\hline & \multicolumn{2}{|l|}{$n=45$} & \multicolumn{2}{|l|}{$n=44^{\mathrm{a}}$} \\
\hline & Any grade & Grade $\geq 3^{b}$ & Any grade & Grade $\geq 3^{b}$ \\
\hline Overall & $37(82.2)$ & $13(28.9)$ & $43(97.7)$ & $20(45.5)$ \\
\hline Diarrhoea & $16(35.6)$ & $2(4.4)$ & $14(31.8)$ & $3(6.8)$ \\
\hline Oedema peripheral & $11(24.4)$ & $0(0.0)$ & $0(0.0)$ & $0(0.0)$ \\
\hline Fatigue & $9(20.0)$ & $2(4.4)$ & $11(25.0)$ & $0(0.0)$ \\
\hline PPES & $8(17.8)$ & $1(2.2)$ & 27 (61.4) & $3(6.8)$ \\
\hline Decreased appetite & $8(17.8)$ & $0(0.0)$ & $12(27.3)$ & $0(0.0)$ \\
\hline $\begin{array}{l}\text { Blood creatinine } \\
\text { increased }\end{array}$ & $6(13.3)$ & $0(0.0)$ & $0(0.0)$ & $0(0.0)$ \\
\hline AST increased & $5(11.1)$ & $2(4.4)$ & $10(22.7)$ & $3(6.8)$ \\
\hline Hypoalbuminaemia & $5(11.1)$ & $0(0.0)$ & $2(4.5)$ & $0(0.0)$ \\
\hline ALT increased & $4(8.9)$ & $0(0.0)$ & 7 (15.9) & $0(0.0)$ \\
\hline Amylase increased & $3(6.7)$ & $2(4.4)$ & $5(11.4)$ & $1(2.3)$ \\
\hline $\begin{array}{l}\text { Blood bilirubin } \\
\text { increased }\end{array}$ & $2(4.4)$ & $1(2.2)$ & $8(18.2)$ & $2(4.5)$ \\
\hline Alopecia & $1(2.2)$ & $0(0.0)$ & $10(22.7)$ & $0(0.0)$ \\
\hline Lipase increased & $1(2.2)$ & $0(0.0)$ & $5(11.4)$ & $4(9.1)$ \\
\hline Hypertension & $0(0.0)$ & $0(0.0)$ & $11(25.0)$ & $6(13.6)$ \\
\hline $\begin{array}{l}\text { Dermatitis } \\
\text { acneiform }\end{array}$ & $0(0.0)$ & $0(0.0)$ & $5(11.4)$ & $0(0.0)$ \\
\hline $\begin{array}{l}\text { ALT alanine aminotra } \\
\text { palmar-plantar erythro } \\
\text { a One patient did not re } \\
{ }^{\mathrm{b}} \text { Grade } \geq 3 \text { treatment-re } \\
\text { ascites }(4.4 \%) \text { and hyp } \\
\text { gamma-glutamyl transf }\end{array}$ & $\begin{array}{l}\text { ferase, } A S \\
\text { sesthesia ss } \\
\text { ive treatm } \\
\text { ted adverse } \\
\text { glycaemia } \\
\text { ase }(4.5 \%) \mathrm{f}\end{array}$ & $\begin{array}{l}T \text { aspartate } \\
\text { yndrome. } \\
\text { ent. } \\
\text { events (in } \geq \\
(4.4 \% \text { ) for } t \\
\text { for sorafenib. }\end{array}$ & aminotrar & $\begin{array}{l}\text { included } \\
\text { increased }\end{array}$ \\
\hline
\end{tabular}

analyses, there was a benefit for tepotinib over sorafenib for every subgroup, except for the small number of female patients (Fig. 2b). Investigator-assessed TTP improved for tepotinib (median, 5.6 months; $90 \% \mathrm{Cl}$ : 3.0-7.6) versus sorafenib (median, 2.8 months; $90 \% \mathrm{Cl}: 1.5-2.8$ months, $\mathrm{HR}=0.45,90 \% \mathrm{Cl}: 0.28-0.73$, $P=0.0059$ ).

An improved PFS assessed by IRC was observed in patients treated with tepotinib versus sorafenib $(\mathrm{HR}=0.53,90 \% \mathrm{Cl}$ : $0.33-0.84, P=0.0229$ ) (Fig. 3a). Median PFS in the tepotinib arm was 2.8 months $(90 \% \mathrm{Cl}$ : $1.4-4.2)$ versus 1.4 months $(90 \% \mathrm{Cl}$ : 1.4-1.6) in the sorafenib arm. The results for investigator-assessed PFS were also improved with tepotinib compared with sorafenib (median PFS was 3.2 [90\% Cl: 2.7-5.6] versus 2.8 [90\% Cl: 1.5-2.8] months, respectively; $\mathrm{HR}=0.59,90 \% \mathrm{Cl}: 0.38-0.92, P=0.0496)$. OS was similar between the study arms, with a median OS of 9.3 months and 8.6 months in the tepotinib and sorafenib arms, respectively ( $\mathrm{HR}=0.73,90 \% \mathrm{Cl}: 0.43-1.21)$ (Fig. 3b).

The ORR by IRC was $10.5 \%$ in the tepotinib arm versus $0 \%$ in the sorafenib treatment arm $(P=0.0438)$ (Table 3$)$. Four patients $(10.5 \%)$ in the tepotinib arm had a best overall response of PR versus no patients in the sorafenib arm; no patients had a best overall response of complete response. As of Sept 2020, one patient with MET IHC 3+, MET amplification and a PR was still receiving treatment with tepotinib (treatment duration $>45$ months). Disease control was achieved by 19 patients (50\%) and eight patients $(21.6 \%)$ in the tepotinib and sorafenib arms, respectively.

Pharmacokinetics

In Phase $1 \mathrm{~b}, \mathrm{AUC}_{\mathrm{t}, \mathrm{ss}}$ of tepotinib was $11,800 \mathrm{ng}^{*} \mathrm{~h} / \mathrm{mL}$ (35.7\%) for the $300 \mathrm{mg}$ dose group, $16,700 \mathrm{ng}^{*} \mathrm{~h} / \mathrm{mL}(29.7 \%)$ for the $500 \mathrm{mg}$ 


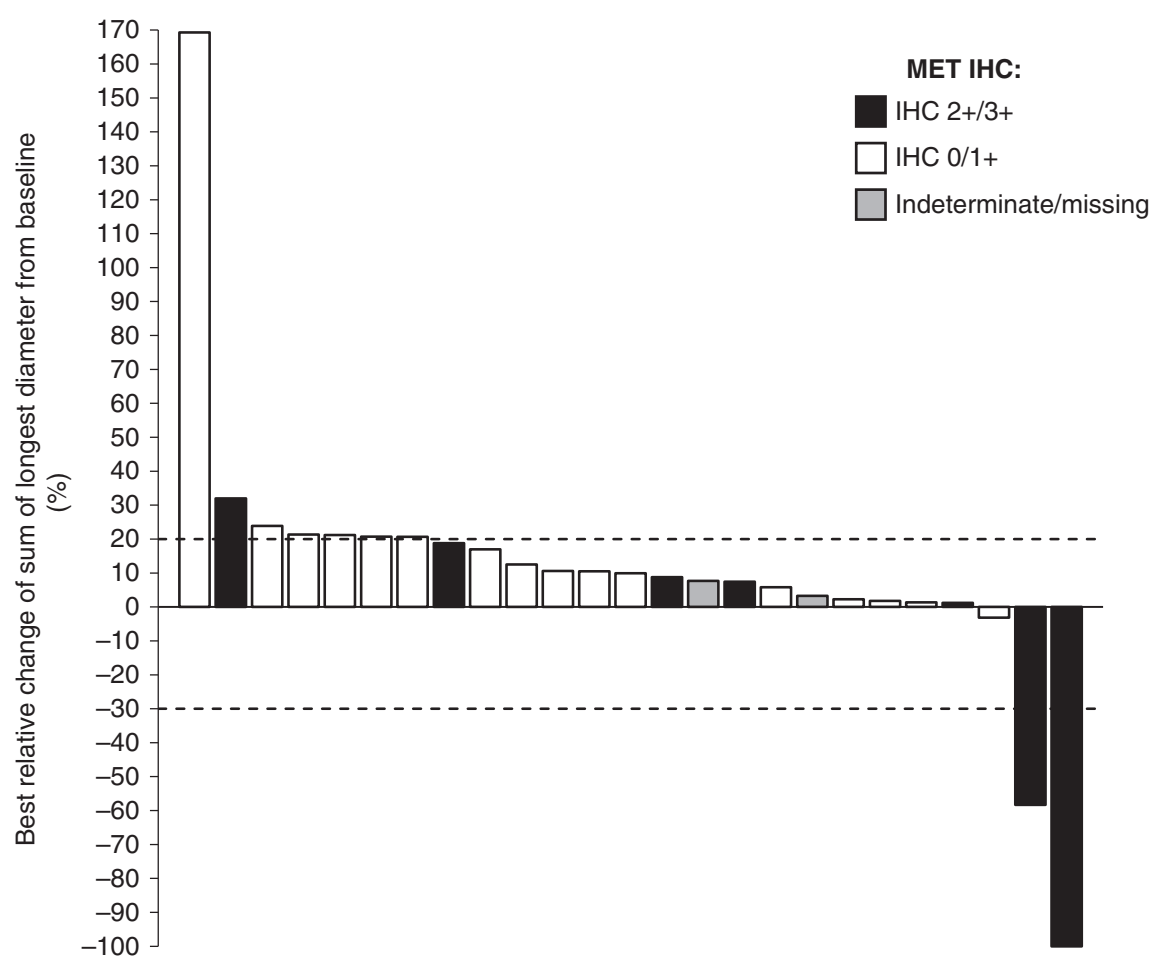

Fig. 1 Relative change in sum of longest diameters of tumour lesions from baseline to post-baseline nadir for RECIST-evaluable patients ( $n=25$, Phase 1b study). IHC immunohistochemistry.

dose group and $28,600 \mathrm{ng}^{*} \mathrm{~h} / \mathrm{mL}(38.8 \%)$ for the $1,000 \mathrm{mg}$ dose group (figures are geometric mean and geometric coefficient of variation). Corresponding values for $C_{\max }$ of tepotinib were 585 $\mathrm{ng} / \mathrm{mL}$ (30.8\%), $815 \mathrm{ng} / \mathrm{mL}$ (31.6\%) and $1,370 \mathrm{ng} / \mathrm{mL}$ (36.3\%), respectively.

\section{DISCUSSION}

The Phase $1 \mathrm{~b}$ portion of the present study confirmed the RP2D of tepotinib for the treatment of Asian patients with advanced HCC to be $500 \mathrm{mg}$ daily. This same dose level has been established as the RP2D in other settings and patient populations, including US/ European patients with solid tumours (the first-in-human study), ${ }^{13}$ Japanese patients with solid tumours ${ }^{19}$ and US/European patients with advanced $\mathrm{HCC}^{20}$ Tepotinib also showed preliminary evidence of antitumour activity in the Phase $1 \mathrm{~b}$ part of the study. In Phase 2, first-line tepotinib demonstrated clinical activity and was generally well tolerated in Asian patients with advanced HCC with MET overexpression (IHC $2+/ 3+$ ). The primary endpoint was met, with a statistically significant improvement in TTP as assessed by IRC with tepotinib versus sorafenib. TTP benefit with tepotinib was seen across subgroups, although patient numbers were small in some subgroups. Greater antitumour activity of tepotinib versus sorafenib was also shown in terms of investigator-assessed TTP, as well as PFS and ORR.

Prior trials of inhibitors with activity against the MET receptor in advanced HCC have produced mixed findings. The non-selective MET inhibitor cabozantinib has been approved for use postsorafenib, following the results from a placebo-controlled Phase 3 trial in MET-unselected $\mathrm{HCC}^{21}$ In contrast, despite positive Phase 2 data, ${ }^{22}$ two Phase 3 trials of tivantinib in sorafenib pre-treated HCC with MET overexpression did not meet their primary endpoints. ${ }^{23,24}$ The selective MET inhibitor capmatinib has demonstrated an ORR of $10 \%$ in a small, single-arm Phase 2 first-line study of 30 patients with HCC with MET alterations (defined by MET H-score $\geq 50, M E T: C E P 7$ ratio $\geq 2.0$ or MET gene copy number $\geq 5$ ). ${ }^{25}$ While differences in trial design and settings prevent direct comparison, differences in the pharmacologic characteristics of the MET inhibitors, evaluated to date, could be relevant for clinical activity. ${ }^{9}$ For example, tepotinib, cabozantinib and capmatinib inhibit MET with in vitro $\mathrm{IC}_{50}$ values in the low nanomolar range, whereas tivantinib has a lower affinity for the receptor. ${ }^{9}$ Furthermore, unlike tepotinib and capmatinib, cabozantinib inhibits several other kinases and tivantinib has antimitotic effects, which may result from inhibition of glycogen synthase kinase-3a/ $\beta .^{9,26,27}$ Although inhibition of other pathways could contribute to anticancer effects, it may also constrain the maximum tolerated dose by increasing toxicity, and thereby limit clinical activity. ${ }^{28}$ Overall, the efficacy and safety of tepotinib shown in the present study lends further support to the strategy of selective MET inhibition in advanced HCC.

Subgroup analyses from the capmatinib study ${ }^{25}$ suggest more stringent definitions for $M E T$ alteration could predict greater benefit from selective MET inhibitors. A possible trend for greater 12-week PFS rates with tepotinib in patients with MET IHC 3+ status (versus 2+) or MET amplification (versus no MET amplification) was also observed in the Phase $1 \mathrm{~b} / 2$ second-line trial. ${ }^{17}$ In the present study, the low number of patients with MET IHC $3+$ staining in the tepotinib arm precludes assessment of the impact of MET IHC status ( $2+$ versus $3+$ ) on the activity of tepotinib versus sorafenib. Similarly, few patients with $M E T$ amplification were enrolled, although the subgroup analysis suggested that the TTP increase with tepotinib relative to sorafenib was similar in these patients compared with patients without MET amplification. The efficacy of tepotinib also appeared consistent, irrespective of alpha-fetoprotein elevation, which is a predictive marker for ramucirumab in the second-line setting. ${ }^{29,30}$

The median TTP of 1.4 months with sorafenib in the control arm of the present study is considerably lower than the 5.5 months in the Phase 3 SHARP sorafenib trial, ${ }^{5}$ and somewhat lower than the 2.8 months in the Phase 3 Asia-Pacific sorafenib trial. ${ }^{4}$ As in the Asia-Pacific trial, median TTP in the present study may have been impacted by the greater representation of patients with BCLC stage $C(96 \%)$ relative to SHARP $(82 \%))^{2,4,5}$ Shorter TTP with 
a

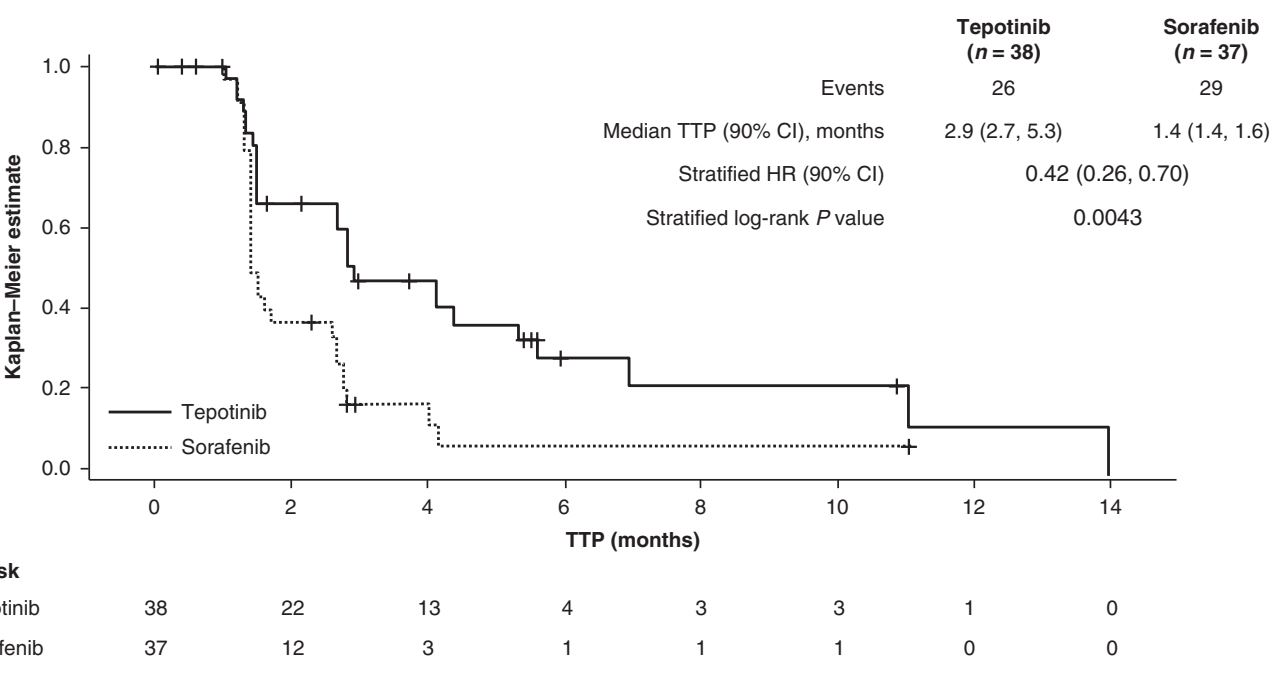

b

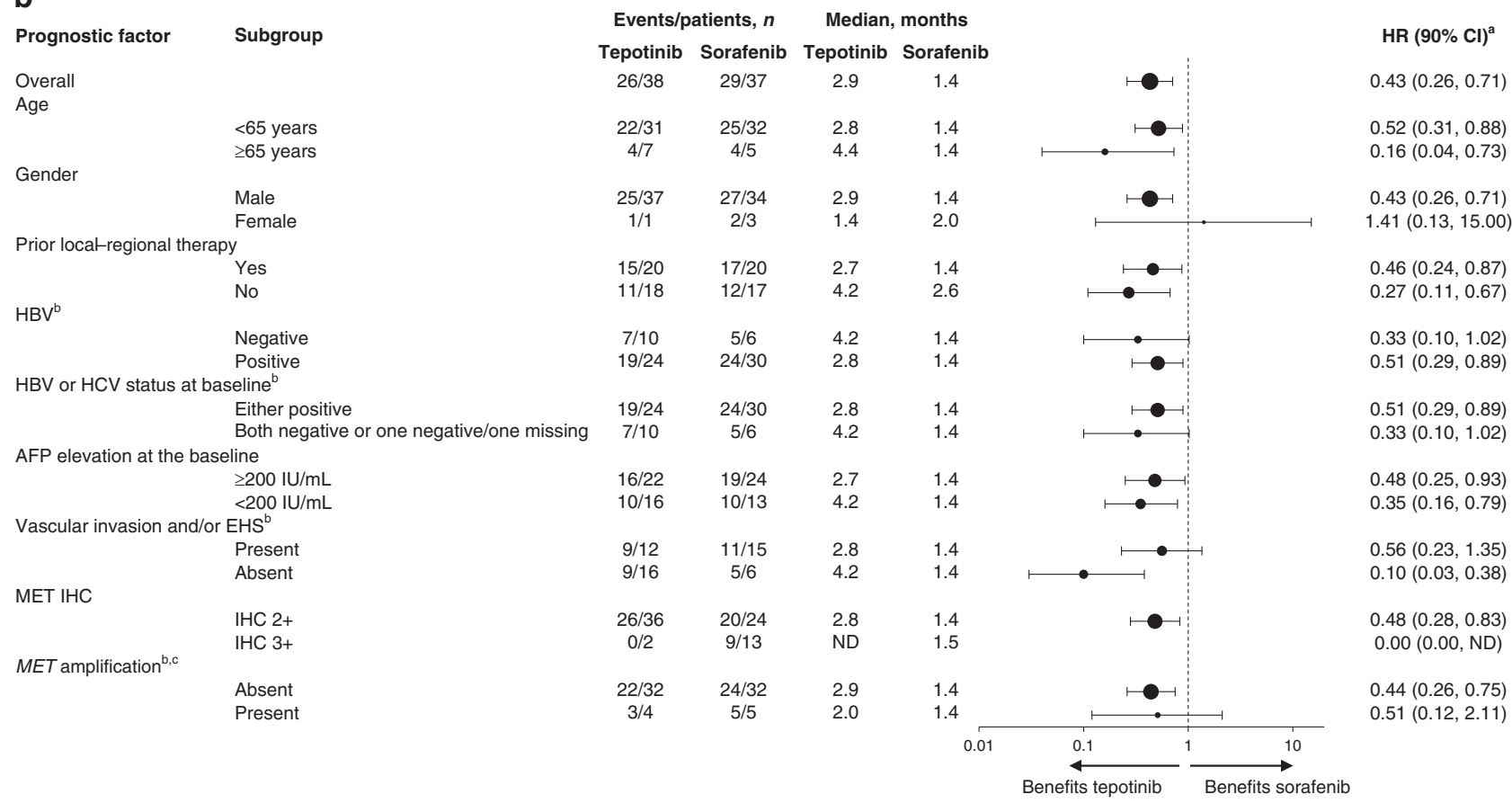

Fig. 2 TTP assessed by IRC (Phase 2 study, mITT analysis set). a Kaplan-Meier curve. b Forest plot showing predefined subgroup analyses. ${ }^{\mathrm{a}}$ Unstratified; ${ }^{\mathrm{b}}$ Information not available for some patients in the tepotinib and/or sorafenib group; ${ }^{\mathrm{C}} M E T$ amplification defined as mean GCN $\geq$ 5. AFP alpha-fetoprotein, Cl confidence interval, EHS extrahepatic spread, GCN gene copy number, HBV hepatitis $B$ virus, HCV hepatitis $C$ virus, $H R$ hazard ratio, IHC immunohistochemistry, IU international units, $\mathrm{mITT}$ modified intent-to-treat, ND not determined, $T T P$ time to progression.

sorafenib could also reflect the high proportion of patients in the control arm of our study with MET IHC 3+ status (35.1\%). Biomarker data from SHARP showing better TTP and OS with sorafenib in patients with lower (versus higher) baseline HGF $^{31}$ suggest that over-activation of the MET signalling pathway may result in poor outcomes with sorafenib. MET IHC status in the present study was imbalanced between arms, and the low number of patients with $3+$ status in the tepotinib arm could also have attenuated efficacy of this agent, given the evidence for association between more stringent definitions of $M E T$ alteration and better outcomes with selective MET inhibitors. ${ }^{17,25}$

Across both phases, tepotinib was generally well tolerated with no new safety signals. No DLTs were observed at any dose in Phase $1 \mathrm{~b}$. The incidence of treatment-related AEs was in line with previously published data, ${ }^{13,15,17,19}$ and no unexpected AEs were reported. Patients treated with tepotinib reported fewer overall and Grade $\geq 3$ treatment-related AEs compared with sorafenib.

With the $500 \mathrm{mg}$ dose in the Phase $1 \mathrm{~b}$ study, tepotinib $A U C_{T}$ was $61 \%$ and $C_{\max }$ was $63 \%$ of that observed in the first-in-human trial. ${ }^{13}$ This is expected given findings from a population pharmacokinetic analysis showing a reduction in tepotinib exposure in patients with cirrhosis, as well as from a dedicated pharmacokinetic hepatic impairment trial. ${ }^{32}$ In the latter study, patients with moderate hepatic impairment (Child-Pugh B) had $12 \%$ lower AUC from time 0 to infinity and $29 \%$ lower $C_{\max }$ compared with control subjects without hepatic impairment. Lower exposure relative to the first-in-human trial was also observed in the Phase $1 \mathrm{~b} / 2$ study in sorafenib pre-treated advanced HCC with MET overexpression. ${ }^{33}$

The selection of sorafenib, as the control treatment, for the present study reflects the standard of care for first-line 


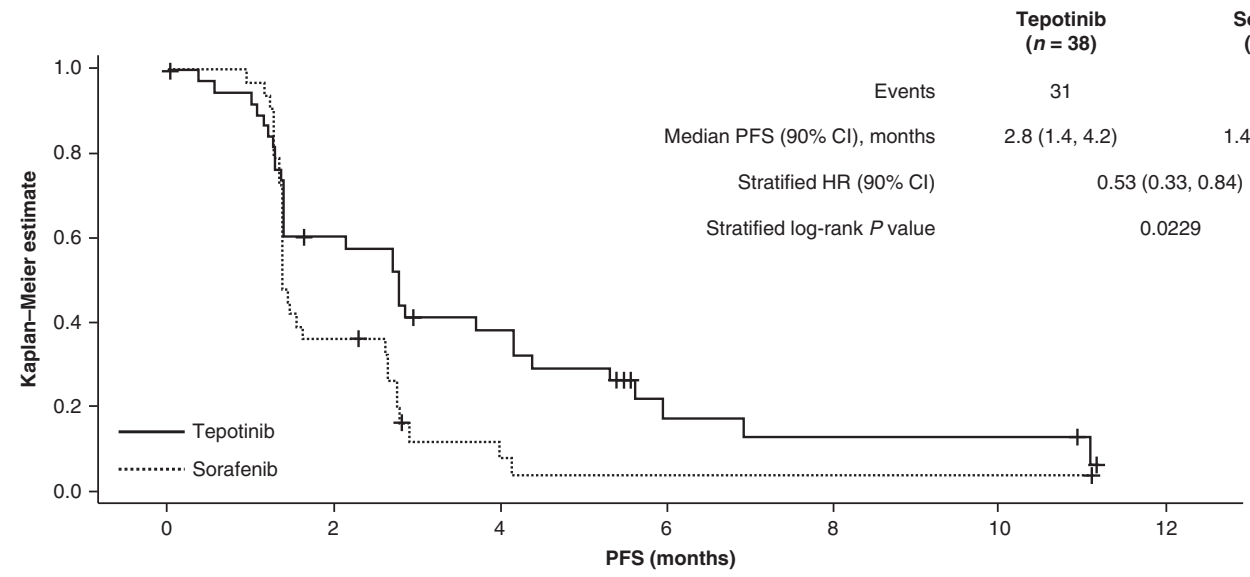

\begin{tabular}{|c|c|c|c|c|c|c|c|}
\hline At risk & & & & & & & \\
\hline Tepotinib & 38 & 22 & 13 & 4 & 3 & 3 & 0 \\
\hline Sorafenib & 37 & 12 & 3 & 1 & 1 & 1 & 0 \\
\hline
\end{tabular}

b

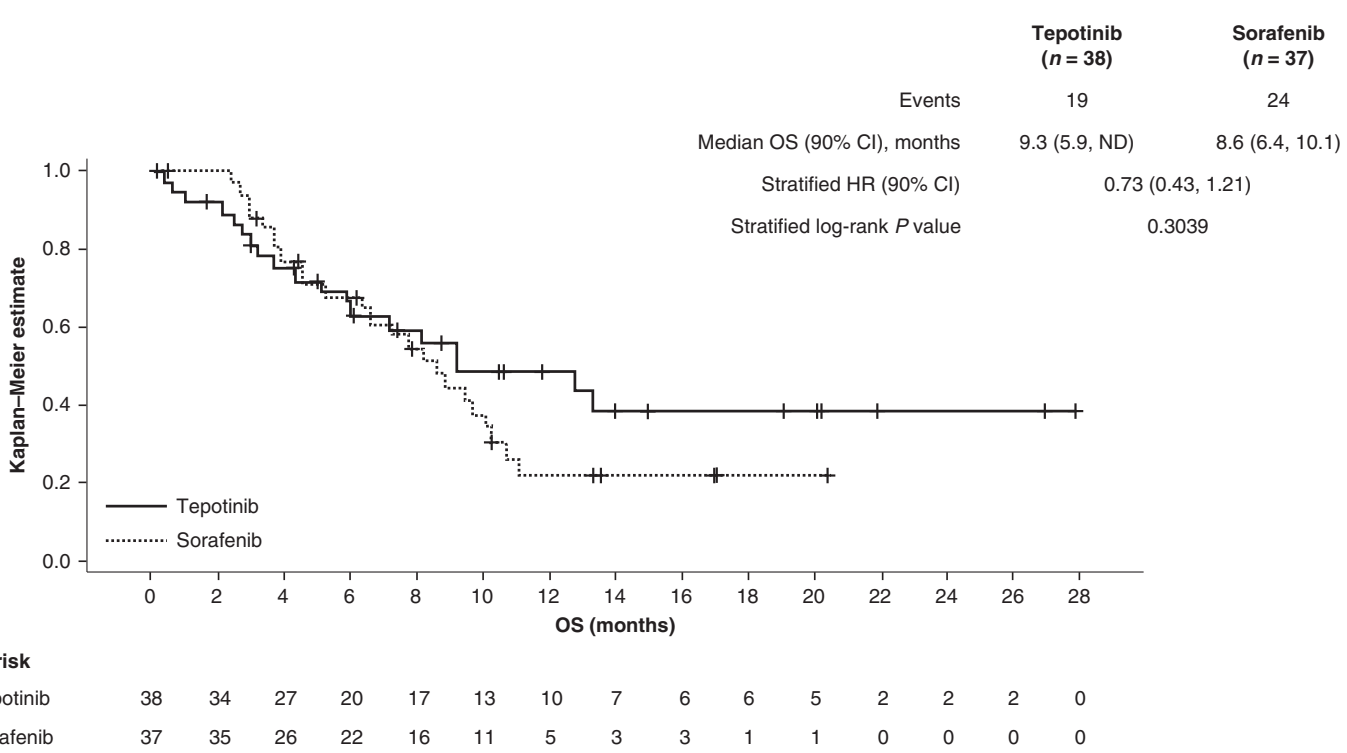

Fig. 3 Kaplan-Meier curves for the Phase 2 study (mITT analysis set). a PFS assessed by IRC. b OS. Cl confidence interval, $H R$ hazard ratio, $I R C$ independent review committee, mITT modified intention-to-treat, ND not determined, OS overall survival, PFS progression-free survival.

treatment at the time of study conception. Since then, both the multikinase inhibitor lenvatinib and the combination of atezolizumab (anti-programmed death-ligand 1 [PD-L1]) plus bevacizumab (anti-vascular endothelial growth factor [VEGF]) have been approved in the first-line setting. ${ }^{6,7}$ After sorafenib failure, approved options include the anti-VEGF receptor-2 agent ramucirumab (for patients with elevated serum alpha-fetoprotein), the multikinase inhibitors regorafenib and cabozantinib and the immune checkpoint inhibitors pembrolizumab and nivolumab ( \pm ipilimumab). ${ }^{21,30,34-38}$ While durable responses to nivolumab were observed in both sorafenib-naive and sorafenib pre-treated patients in the Phase 1/2 CheckMate 040 study, 37,39 first-line nivolumab did not show an OS benefit compared with sorafenib in the Phase 3 CheckMate 459 trial. $^{40}$ Other immunotherapy-containing strategies currently undergoing Phase 3 evaluation in previously untreated disease include durvalumab (anti-PD-L1), alone or in combination with a second immunotherapy (tremelimumab, anti-cytotoxic T-lymphocyteassociated protein-4; NCT03298451), lenvatinib plus pembrolizumab (LEAP-002; NCT03713593) and cabozantinib plus atezolizumab (COSMIC-312; ${ }^{41}$ NCT03755791). Given the favourable safety profile of tepotinib and the immunosuppressive function of MET signalling, ${ }^{42}$ use of tepotinib in combination with immunotherapies could be an interesting area for future study.

Strengths of the current study include the randomised design, which permitted evaluation of tepotinib efficacy relative to an established standard of care in this setting. Limitations include the non-blinded treatment assignment and the low proportions of patients with MET amplification or MET IHC 3+ status, which limited explorations of the impact of MET-based biomarkers on efficacy. The study was also underpowered following early termination of enrolment due to slow accrual, but nonetheless demonstrated significant improvements in activity endpoints with tepotinib versus sorafenib. As has been discussed for other studies in HCC with biomarker-driven patient selection, ${ }^{23,24}$ one challenge in this setting is the potential for patients with the most aggressive forms of disease to be excluded, due to rapid progression and/or clinical deterioration, while central biomarker assessments are ongoing, which could have contributed to ineligibility at screening. Finally, it is not known to what extent these results obtained in Asian patients, who were predominantly male with $B C L C$ stage $B$, can be generalised to other populations. 
Table 3. Best overall response as determined by IRC (Phase 2 study; mITT analysis set).

\begin{tabular}{|c|c|c|}
\hline & $\begin{array}{l}\text { Tepotinib } \\
n=38\end{array}$ & $\begin{array}{l}\text { Sorafenib } \\
n=37\end{array}$ \\
\hline \multicolumn{3}{|l|}{ Best overall response } \\
\hline Complete response & $0(0.0)$ & $0(0.0)$ \\
\hline Partial response & $4(10.5)$ & $0(0.0)$ \\
\hline $\begin{array}{l}\text { Non-complete response/non-partial } \\
\text { response }^{a}\end{array}$ & $2(5.3)$ & $0(0.0)$ \\
\hline Stable disease & $15(39.5)$ & $8(21.6)$ \\
\hline Progressive disease & $13(34.2)$ & $25(67.6)$ \\
\hline Not evaluable & $4(10.5)$ & $4(10.8)$ \\
\hline Objective response rate, $n$ (\%) & $4(10.5)$ & $0(0.0)$ \\
\hline $90 \% \mathrm{Cl}^{\mathrm{b}} \%$ & $4.8,21.5$ & $0.0,6.8$ \\
\hline$P$ value (CMH test) & \multicolumn{2}{|c|}{0.0438} \\
\hline Disease control rate, $n$ (\%) & $19(50.0)$ & 8 (21.6) \\
\hline $90 \% \mathrm{Cl}^{\mathrm{b}} \%$ & $37.1,62.9$ & $12.6,34.5$ \\
\hline \multicolumn{3}{|c|}{$\begin{array}{l}\mathrm{Cl} \text { confidence interval, } C M H \text { Cochran-Mantel-Haenszel, IRC independent } \\
\text { review committee, mITT modified intention-to-treat. } \\
\text { a Non-complete response/non-partial response was defined as persistence } \\
\text { of one or more non-target lesion(s) and/or maintenance of tumour marker } \\
\text { level, if measured, above the normal limits (possible only for patients } \\
\text { without measureable disease at baseline). } \\
\text { b } 90 \% \text { Cl using the Newcombe-Wilson method. }\end{array}$} \\
\hline
\end{tabular}

In the Phase $1 \mathrm{~b}$ part of this study, no DLTs were reported and the RP2D was established as 500 mg QD. Evidence of antitumour activity was seen at the $500 \mathrm{mg}$ and 1,000 mg dose levels. In Phase 2, first-line tepotinib (500 mg QD) demonstrated clinical activity in Asian patients with advanced HCC with MET overexpression (IHC $2+/ 3+)$, with a significant improvement versus sorafenib in the primary endpoint of TTP, as well as PFS and ORR. Tepotinib was generally well tolerated and no new safety signals were observed.

\section{ACKNOWLEDGEMENTS}

The authors would like to thank patients, investigators, co-investigators and the study teams at all participating centres and at Merck KGaA, Darmstadt, Germany, and Merck Serono Pharmaceutical R\&D Co., Ltd., Beijing, China (an affiliate of Merck KGaA, Darmstadt, Germany). Part of this paper has been previously presented at congresses: Qin, S., Kim, T.-Y., Lim, H.Y., Ryoo, B.-Y., Scheele, J., Zhou, D. et al. Phase lb trial of tepotinib in Asian patients with advanced hepatocellular carcinoma (HCC): final data including long-term outcomes. J. Clin. Oncol. 35(Suppl 15): abstract 4087 (2017). Qin, S., Kim, T.-Y., Lim, H.Y., Ryoo, B.-Y., Zhou, D., Zhao, C., Becker, A. et al. Final data from a phase $\mathrm{lb}$ trial of tepotinib in Asian patients with advanced hepatocellular carcinoma (HCC). Ann. Oncol. 28(Suppl 5): abstract 701 P (2017). Ryoo, B.Y., Ren, Z., Kim, T.-Y., Pan, H., Rau, K.-M., Choi, H.J. et al. Phase 2 trial of tepotinib vs sorafenib for treatment-naïve advanced hepatocellular carcinoma (HCC) in Asian patients. Ann. Oncol. 29(Suppl 9): abstract 186 P (2018). Qin, S., Ryoo, B.-Y., Decaens, T., Bruns, R., Zhou, D., Scheele, J. et al. Safety of tepotinib in patients with MET overexpressing $(\mathrm{MET}+)$ advanced hepatocellular carcinoma (HCC): outcomes from two studies. Liver Cancer 8(Suppl 1): abstract O-042 (2019).

\section{AUTHOR CONTRIBUTIONS}

All authors participated fully in developing and reviewing the paper for publication with final approval for submission. B-Y.R. and S.Q. were involved in conceptualisation, data curation, formal analysis, investigation, supervision and validation. A.C. was involved in data curation, investigation, supervision and validation. J.H.K. and H.P. were involved in investigation and resources. K-M.R. was involved in investigation and project administration. C.J.Y. was involved in investigation, data curation and visualisation of the paper. K.B., D.Z. and J.S. were involved in formal analysis, investigation and validation. H.Y.L. was involved in conceptualisation, data curation, investigation, validation and visualisation. Z.R., T-Y.K., H.J.C. and J-W.P. were involved in investigation. J.Sc. was involved in conceptualisation, data curation, formal analysis, investigation and supervision (Medical Lead).

\section{ADDITIONAL INFORMATION}

Ethics approval and consent to participate All patients provided written informed consent for participation in the study. The study was conducted in accordance with the Declaration of Helsinki. This study has been reviewed and approved by the respective Institutional Review Boards/Independent Ethics Committees according to national and international regulations (Supplementary Table 5).

Consent to publish Not applicable.

Data availability Data are held by the sponsor Merck KGaA (Darmstadt, Germany), to whom any request for additional data should be addressed.

Competing interests Ann-Lii Cheng has provided consulting for AstraZeneca, BristolMyers Squibb, Eisai, Merck KGaA, Novartis, Ono Pharmaceutical, Exelixis, IPSEN Innovation, Bayer Healthcare, Merck Sharp Dohme, Roche/Genentech, BeiGene, CSR Pharma Group, F. Hoffmann-La Roche and IQVIA; attended speakers' bureau for Bayer Yakuhin Ltd., Novartis, Eisai, Ono Pharmaceutical and Amgen Taiwan; received travel grants from Bayer Yakuhin Ltd, Roche/Genentech and IQVIA. Joong-Won Park participated in consultant and advisory boards for AstraZeneca, Ipsen, Bristol-Myers Squibb, Roche and Bayer, and attended speaker's bureau for Bayer, Ipsen and Eisai. Ho Yeong Lim attended advisory boards for Bayer, Eisai, Ono Pharmaceuticals, BristolMyers Squibb, Merck KGaA, Ipsen, AstraZeneca, and attended speaker's bureau for Bayer. Baek-Yeol Ryoo, Zhenggang Ren, Tae-You Kim, Hongming Pan, Kun-Ming Rau, Hye Jin Choi, Jee Hyun Kim, Chia Jui Yen and Shukui Qin have nothing to declare. Juergen Scheele was an employee of Merck KGaA, Darmstadt, Germany, at the time the work was conducted. Karin Berghoff, Josef Straub and Dongli Zhou are employees of Merck KGaA, Darmstadt, Germany and also hold stocks with the company.

Funding information The sponsor, Merck KGaA, Darmstadt, Germany, provided the study drug and worked with investigators on the trial design and plan, collection and analyses of data, and interpretation of results. Data sets were reviewed by the authors, and all authors participated fully in developing and reviewing the paper for publication. Funding for a professional medical writer with access to the data was provided by the sponsor for initial drafts of the paper. All authors had full access to all the data in the study and had final responsibility for the decision to submit for publication. Medical writing assistance was provided by Helen Swainston (Bioscript Science, Macclesfield, UK), Jack Eaton (Syneos Health, UK) and Mark Dyson, DPhil (Berlin, Germany), and was funded by Merck KGaA, Darmstadt, Germany.

Supplementary information The online version contains supplementary material available at https://doi.org/10.1038/s41416-021-01380-3.

Publisher's note Springer Nature remains neutral with regard to jurisdictional claims in published maps and institutional affiliations.

\section{REFERENCES}

1. Sayiner, M., Golabi, P. \& Younossi, Z. M. Disease burden of hepatocellular carcinoma: a global perspective. Dig. Dis. Sci. 64, 910-917 (2019).

2. Raoul, J. L., Kudo, M., Finn, R. S., Edeline, J., Reig, M. \& Galle, P. R. Systemic therapy for intermediate and advanced hepatocellular carcinoma: Sorafenib and beyond. Cancer Treat. Rev. 68, 16-24 (2018).

3. Bruix, J., da Fonseca, L. G. \& Reig, M. Insights into the success and failure of systemic therapy for hepatocellular carcinoma. Nat. Rev. Gastroenterol. Hepatol. 16, 617-630 (2019).

4. Cheng, A. L., Kang, Y. K., Chen, Z., Tsao, C. J., Qin, S., Kim, J. S. et al. Efficacy and safety of sorafenib in patients in the Asia-Pacific region with advanced hepatocellular carcinoma: a phase III randomised, double-blind, placebo-controlled trial. Lancet Oncol. 10, 25-34 (2009).

5. Llovet, J. M., Ricci, S., Mazzaferro, V., Hilgard, P., Gane, E., Blanc, J. F. et al. Sorafenib in advanced hepatocellular carcinoma. N. Engl. J. Med. 359, 378-390 (2008)

6. Kudo, M., Finn, R. S., Qin, S., Han, K.-H., Ikeda, K., Piscaglia, F. et al. Lenvatinib versus sorafenib in first-line treatment of patients with unresectable hepatocellular carcinoma: a randomised phase 3 non-inferiority trial. Lancet 391, 1163-1173 (2018). 
7. Finn, R. S., Qin, S., Ikeda, M., Galle, P. R., Ducreux, M., Kim, T. Y. et al. Atezolizumab plus bevacizumab in unresectable hepatocellular carcinoma. N. Engl. J. Med. 382 , 1894-1905 (2020)

8. Tecentriq (atezolizumab) US Prescribing Information (2020).

9. Bouattour, M., Raymond, E., Qin, S., Cheng, A.-L., Stammberger, U., Locatelli, G. et al. Recent developments of c-Met as a therapeutic target in hepatocellular carcinoma. Hepatology 67, 1132-1149 (2018).

10. Lee, S. J., Lee, J., Sohn, I., Mao, M., Kai, W., Park, C.-K. et al. A survey of C-MET expression and amplification in 287 patients with hepatocellular carcinoma. Anticancer Res. 33, 5179-5186 (2013).

11. You, H., Ding, W., Dang, H., Jiang, Y. \& Rountree, C. B. c-Met represents a potential therapeutic target for personalized treatment in hepatocellular carcinoma. Hepatology 54, 879-889 (2011).

12. Bladt, F., Friese-Hamim, M., Ihling, C., Wilm, C. \& Blaukat, A. The c-Met inhibitor MSC2156119J effectively inhibits tumor growth in liver cancer models. Cancers (Basel). 6, 1736-1752 (2014).

13. Falchook, G. S., Kurzrock, R., Amin, H. M., Xiong, W., Fu, S., Piha-Paul, S. A. et al. First-in-man phase I trial of the selective MET inhibitor tepotinib in patients with advanced solid tumors. Clin. Cancer Res. 26, 1237-1246 (2020).

14. Park, K., Felip, E., Veillon, R., Cortot, A., Mazieres, J., Sakai, H. et al. Tepotinib in NSCLC patients harboring METex14 skipping: Cohort A of phase II VISION study. Ann. Oncol. 30, ix22-ix29 (2019).

15. Paik, P. K., Felip, E., Veillon, R., Sakai, H., Cortot, A. B., Garassino, M. C. et al. Tepotinib in non-small-cell lung cancer with MET exon 14 skipping mutations. $N$. Engl. J. Med. 383, 931-943 (2020).

16. Wu, Y. L., Cheng, Y., Zhou, J., Lu, S., Zhang, Y., Zhao, J. et al. Tepotinib plus gefitinib in patients with EGFR-mutant non-small-cell lung cancer with MET overexpression or MET amplification and acquired resistance to previous EGFR inhibitor (INSIGHT study): an open-label, phase $1 \mathrm{~b} / 2$, multicentre, randomised trial. Lancet Res. Med. 8, 1132-1143 (2020).

17. Decaens, T., Barone, C., Assenat, E., Wermke, M., Fasolo, A., Merle, P. et al. Efficacy and safety of the Met inhibitor tepotinib in patients (pts) with advanced Met + hepatocellular carcinoma (HCC) previously treated with sorafenib. Ann. Oncol. 29, ix48 (2018).

18. Cappuzzo, F., Marchetti, A., Skokan, M., Rossi, E., Gajapathy, S., Felicioni, L. et al. Increased MET gene copy number negatively affects survival of surgically resected non-small-cell lung cancer patients. J. Clin. Oncol. 27, 1667-1674 (2009).

19. Shitara, K., Yamazaki, K., Tsushima, T. Naito, T. Matsubara, N. \& Watanabe, M. Phase I trial of the MET inhibitor tepotinib in Japanese patients with solid tumors. Jpn. J. Clin. Oncol. 50, 859-866 (2020).

20. Faivre, S. J., Blanc, J.-F., Merle, P., Fasolo, A., lacobellis, A., Decaens, T. et al. Final phase $\mathrm{lb}$ data for the oral c-Met inhibitor tepotinib in patients with previously treated advanced hepatocellular carcinoma. J. Clin. Oncol. 35, e15676 (2017).

21. Abou-Alfa, G. K., Meyer, T., Cheng, A.-L., El-Khoueiry, A. B., Rimassa, L., Ryoo, B.-Y. et al. Cabozantinib in patients with advanced and progressing hepatocellular carcinoma. N. Engl. J. Med. 379, 54-63 (2018).

22. Santoro, A., Rimassa, L., Borbath, I., Daniele, B., Salvagni, S., Van Laethem, J. L. et al. Tivantinib for second-line treatment of advanced hepatocellular carcinoma: a randomised, placebo-controlled phase 2 study. Lancet Oncol. 14, 55-63 (2013).

23. Rimassa, L., Assenat, E., Peck-Radosavljevic, M., Pracht, M., Zagonel, V., Mathurin, P. et al. Tivantinib for second-line treatment of MET-high, advanced hepatocellular carcinoma (METIV-HCC): a final analysis of a phase 3, randomised, placebocontrolled study. Lancet Oncol. 19, 682-693 (2018).

24. Kudo, M., Morimoto, M., Moriguchi, M., Izumi, N., Takayama, T., Yoshiji, H. et al. A randomized, double-blind, placebo-controlled, phase 3 study of tivantinib in Japanese patients with MET-high hepatocellular carcinoma. Cancer Sci. 111, 3759-3769 (2020)

25. Oin, S., Chan, S. L., Sukeepaisarnjaroen, W., Han, G., Choo, S. P., Sriuranpong, V. et al. A phase II study of the efficacy and safety of the MET inhibitor capmatinib (INC280) in patients with advanced hepatocellular carcinoma. Ther. Adv. Med. Oncol. 11, 1758835919889001 (2019).

26. Basilico, C., Pennacchietti, S., Vigna, E., Chiriaco, C., Arena, S., Bardelli, A. et al. Tivantinib (ARQ197) displays cytotoxic activity that is independent of its ability to bind MET. Clin. Cancer Res. 19, 2381-2392 (2013).

27. Remsing Rix, L. L., Kuenzi, B. M., Luo, Y., Remily-Wood, E., Kinose, F., Wright, G. et al. GSK3 alpha and beta are new functionally relevant targets of tivantinib in lung cancer cells. ACS Chem. Bio. 9, 353-358 (2014).

28. Wu, Y. L., Soo, R. A., Locatelli, G., Stammberger, U., Scagliotti, G. \& Park, K. Does c-Met remain a rational target for therapy in patients with EGFR TKI-resistant nonsmall cell lung cancer? Cancer Treat. Rev. 61, 70-81 (2017).
29. Zhu, A. X., Park, J. O., Ryoo, B. Y., Yen, C. J., Poon, R., Pastorelli, D. et al. Ramucirumab versus placebo as second-line treatment in patients with advanced hepatocellular carcinoma following first-line therapy with sorafenib (REACH): a randomised, double-blind, multicentre, phase 3 trial. Lancet Oncol. 16, 859-870 (2015).

30. Zhu, A. X., Kang, Y. K., Yen, C. J., Finn, R. S., Galle, P. R., Llovet, J. M. et al. Ramucirumab after sorafenib in patients with advanced hepatocellular carcinoma and increased alpha-fetoprotein concentrations (REACH-2): a randomised, double-blind, placebo-controlled, phase 3 trial. Lancet Oncol. 20, 282-296 (2019).

31. Llovet, J. M., Pena, C. E., Lathia, C. D., Shan, M., Meinhardt, G., Bruix, J. et al. Plasma biomarkers as predictors of outcome in patients with advanced hepatocellular carcinoma. Clin. Cancer Res. 18, 2290-2300 (2012).

32. Tepotinib Japanese Package Insert (2020).

33. Decaens, T., Barone, C., Assenat, E., Wermke, M., Fasolo, A., Merle, P. et al. Phase $1 \mathrm{~b} / 2$ trial of tepotinib in sorafenib pretreated advanced hepatocellular carcinoma with MET overexpression. Br. J. Cancer https://doi.org/10.1038/s41416-021-013349 (2021).

34. Bruix, J., Qin, S., Merle, P., Granito, A., Huang, Y. H., Bodoky, G. et al. Regorafenib for patients with hepatocellular carcinoma who progressed on sorafenib treatment (RESORCE): a randomised, double-blind, placebo-controlled, phase 3 trial. Lancet 389, 56-66 (2017).

35. Zhu, A. X., Finn, R. S., Edeline, J., Cattan, S., Ogasawara, S., Palmer, D. et al. Pembrolizumab in patients with advanced hepatocellular carcinoma previously treated with sorafenib (KEYNOTE-224): a non-randomised, open-label phase 2 trial. Lancet Oncol. 19, 940-952 (2018).

36. Finn, R. S., Ryoo, B. Y., Merle, P., Kudo, M., Bouattour, M., Lim, H. Y. et al. Pembrolizumab as second-line therapy in patients with advanced hepatocellular carcinoma in KEYNOTE-240: a randomized, double-blind, Phase III trial. J. Clin. Oncol. 38, 193-202 (2020).

37. El-Khoueiry, A. B., Sangro, B., Yau, T., Crocenzi, T. S., Kudo, M., Hsu, C. et al. Nivolumab in patients with advanced hepatocellular carcinoma (CheckMate 040): an open-label, non-comparative, phase $1 / 2$ dose escalation and expansion trial. Lancet 389, 2492-2502 (2017).

38. Yau, T., Kang, Y.-K., Kim, T.-Y., El-Khoueiry, A. B., Santoro, A., Sangro, B. et al. Efficacy and safety of nivolumab plus ipilimumab in patients with advanced hepatocellular carcinoma previously treated with sorafenib: the CheckMate 040 randomized clinical trial. JAMA Oncol. 6, e204564 (2020).

39. Crocenzi, T. S., El-Khoueiry, A. B., Yau, T. C., Melero, I., Sangro, B., Kudo, M. et al. Nivolumab (nivo) in sorafenib (sor)-naive and -experienced pts with advanced hepatocellular carcinoma (HCC): CheckMate 040 study. J. Clin. Oncol. 35, 4013 (2017).

40. Yau, T., Park, J. W., Finn, R. S., Cheng, A. L., Mathurin, P., Edeline, J. et al. CheckMate 459: A randomized, multi-center phase III study of nivolumab (NIVO) vs sorafenib (SOR) as first-line (1L) treatment in patients (pts) with advanced hepatocellular carcinoma (aHCC). Ann. Oncol. 30, v874-v875 (2019).

41. Kelley, R. K., J, W. O., Hazra, S., Benzaghou, F., Yau, T., Cheng, A. L. et al. Cabozantinib in combination with atezolizumab versus sorafenib in treatment-naive advanced hepatocellular carcinoma: COSMIC-312 Phase III study design. Future Oncol. 16, 1525-1536 (2020).

42. Papaccio, F., Della Corte, C. M., Viscardi, G., Di Liello, R., Esposito, G., Sparano, F. et al. HGF/MET and the immune system: relevance for cancer immunotherapy. Int. J. Mol. Sci. 19, 3295 (2018).

Open Access This article is licensed under a Creative Commons Attribution 4.0 International License, which permits use, sharing, adaptation, distribution and reproduction in any medium or format, as long as you give appropriate credit to the original author(s) and the source, provide a link to the Creative Commons license, and indicate if changes were made. The images or other third party material in this article are included in the article's Creative Commons license, unless indicated otherwise in a credit line to the material. If material is not included in the article's Creative Commons license and your intended use is not permitted by statutory regulation or exceeds the permitted use, you will need to obtain permission directly from the copyright holder. To view a copy of this license, visit http://creativecommons. org/licenses/by/4.0/.

(c) The Author(s) 2021 